\title{
The Effect of Tinospora crispa on Serum Glucose and Insulin Levels in Patients with Type 2 Diabetes Mellitus
}

\author{
Theerawut Klangjareonchai and Chulaporn Roongpisuthipong \\ Department of Medicine, Ramathibodi Hospital, Faculty of Medicine, Mahidol University, Bangkok 10400, Thailand \\ Correspondence should be addressed to Chulaporn Roongpisuthipong, racrp@mahidol.ac.th
}

Received 27 July 2011; Revised 15 August 2011; Accepted 25 August 2011

Academic Editor: Masa-Aki Shibata

Copyright ( $\odot 2012$ T. Klangjareonchai and C. Roongpisuthipong. This is an open access article distributed under the Creative Commons Attribution License, which permits unrestricted use, distribution, and reproduction in any medium, provided the original work is properly cited.

\begin{abstract}
Objective. To determine the effects of Tinospora crispa on serum glucose and insulin levels in healthy subjects and patients with type 2 diabetes mellitus. Method. Serum from 10 healthy subjects and 10 diabetic participants, who had fasted overnight, were obtained every 30-60 minutes during the 3 hours of continued fasting and during the 3 hours after ingestion of $75 \mathrm{~g}$ of glucose with or without ingestion of 125 or $250 \mathrm{~g}$ of Tinospora crispa dry powder capsule. Glucose and Insulin levels were analyzed and the areas under the curve for mean serum glucose and insulin levels were calculated. Result. The areas under the curve of mean serum glucose and insulin levels in both healthy and diabetic participants were not significantly different between with or without Tinospora crispa dry powder capsule. In diabetic participants the area under the curve of glucose was slightly lesser when $250 \mathrm{mg}$ of Tinospora crispa was ingested, but not reaching statistical significance ( 478 and $444 \mathrm{mg} \mathrm{min} / \mathrm{ml}$, resp., $P=0.57$ ). Conclusion. The results suggest that Tinospora crispa ingestion cannot affect serum glucose and insulin levels in healthy subjects or patients with type 2 diabetes mellitus.
\end{abstract}

\section{Introduction}

Diabetes mellitus (DM), one of the major non-communicable diseases, has become a major public health problem and has increased prevalence in the modern world, even in developing countries such as Thailand [1]. As with other diseases, DM has been treated by oral administration of plant extracts based on traditional medicine since ancient times [2]. Tinospora crispa (T. crispa, Menispermaceae), a medicinal plant used to treat DM, was able to cause a reduction in serum glucose level in diabetic rats, and the hypoglycemic effect was probably due to its insulinotropic activity [3]. T. crispa also increased peripheral utilization of glucose and inhibited hepatic glucose release [4].

Sangsuwan et al. [5] showed that T. crispa had no efficacy for therapy in patients with type $2 \mathrm{DM}$ who did not respond to an adequate dose of oral hypoglycemic drugs for at least 2 months and still had a glycosylated hemoglobin of greater than $8.5 \%$. There were no significant changes in fasting serum glucose or glycosylated hemoglobin between those collected at baseline and during the study period in either group. In this study the author suggests that T. crispa did not stimulate insulin secretion in poor controlled diabetes because these patients might not the have ability to secrete insulin. Efficacy of T. crispa should be investigated in diabetic patient who responded to oral hypoglycemic drugs and did not use insulin therapy because pancreas in these patients might have ability of insulinotropic activity.

The objective of this study was to determine the effects of T. crispa on serum glucose and insulin levels in patients with type $2 \mathrm{DM}$ and healthy subjects.

\section{Material and Method}

2.1. Subjects. After approval from the Ethics Committee for Human Studies of Ramathibodi Hospital, Mahidol University, 10 participants ( 7 women and 3 men) with type $2 \mathrm{DM}$ between the ages of 32 and 64 years and 10 healthy participants ( 6 women and 4 men) with normal oral glucose tolerance test between the ages of 23 and 33 years were enrolled, type 2 DM participants responded to oral hypoglycemic drugs and discontinued oral hypoglycemic drugs at least 1 month. Patients with liver disease, heart disease, renal impairment, or those who previously received traditional medicine 
TABLE 1: Baseline characteristics of the subjects in the study.

\begin{tabular}{lcc}
\hline Characteristics & Diabetic participants $(n=10)$ & Healthy participants $(n=10)$ \\
\hline Gender, male $:$ female & $7: 3$ & $6: 4$ \\
Mean age, year (SD) & $54.5(9.5)$ & $27.6(2.9)$ \\
Mean FPG, mg/dL (SD) & $151.0(57.1)$ & $83.4(11.3)$ \\
Mean HbAlc, \% (SD) & $7.7(1.1)$ & $5.8(0.3)$ \\
Mean creatinine, mg/dL (SD) & $0.9(0.5)$ & $0.8(0.2)$ \\
Mean cholesterol, mg/dL (SD) & $175.5(26.6)$ & $204.0(35.7)$ \\
Mean triglyceride, mg/dL (SD) & $131.2(56.7)$ & $85.0(26.4)$ \\
Mean AST, U/L (SD) & $32.2(13.6)$ & $16.9(5.7)$ \\
Mean ALT, U/L (SD) & $46.6(21.0)$ & $29.7(5.3)$ \\
Mean bilirubin, mg/dL (SD) & $0.6(0.3)$ & $0.6(0.4)$ \\
\hline
\end{tabular}

were excluded. Informed, written consent was obtained from all subjects after explanation of the nature, purpose, and potential risks of the study.

2.2. Plant Material and Fraction Preparation. The stems of T. crispa were collected from Supanburi and Nakhonsithammarat provinces, Thailand. Plant material was identified by Dr. Kongkathip N, Department of Chemistry, Faculty of Science, Kasetsart University. Coarse powder of T. crispa stem was defatted with petroleum ether $\left(60-80^{\circ} \mathrm{C}\right)$ and dried material was extracted with $70 \%$ ethanol using soxhlet apparatus at $65-70^{\circ} \mathrm{C}$ for 7 days. The extract was dried under vacuum in a rotary evaporator. Powder was used microcrystalline cellulose at $7 \%$ of powder weight and using dry granulation technique. Powder of 125 and $250 \mathrm{mg} \mathrm{T}$. crispa stem was prepared in form of capsule [6]. We designed to use $250 \mathrm{mg}$ of $T$. crispa dry powder capsule because in previous study, $250 \mathrm{mg}$ twice a day $T$. crispa can reduce fasting blood glucose significantly from baseline in metabolic syndrome patients [7].

2.3. Methods. After the screening visit, all subjects adhered to an alcohol-free, high-carbohydrate diet $(>150 \mathrm{~g} / \mathrm{d})$ and discontinued all oral hypoglycemic agents at least 72 hours before the study. Exercise was discontinued 24 hours before and fasting was instituted 12 hours till the morning of the study. The study was performed in three visits, 1 to 2 weeks apart. The doses at each visit were as follows: $75 \mathrm{~g}$ of glucose at first visit; $75 \mathrm{~g}$ of glucose and $125 \mathrm{mg}$ of $T$. crispa dry powder capsule at second visit; $75 \mathrm{~g}$ of glucose and $250 \mathrm{mg}$ of T. crispa dry powder capsule at third visit. Venous blood was drawn and then ingestion of 75 g glucose with or without ingestion of 125 or $250 \mathrm{mg}$ of T. crispa. Additional venous blood samples were drawn at 30, 60, 90, 120, and 180 minutes after ingestion. Serum glucose was obtained by an automated glucose oxidase method and serum insulin was measured by radioimmunoassay kit. All participants were examined and blood was taken for complete blood count, liver enzyme profile, and renal function at entry and end of the study.

2.4. Statistical Analyses. Areas under the curve (AUC) for increase in serum glucose and serum insulin were calculated

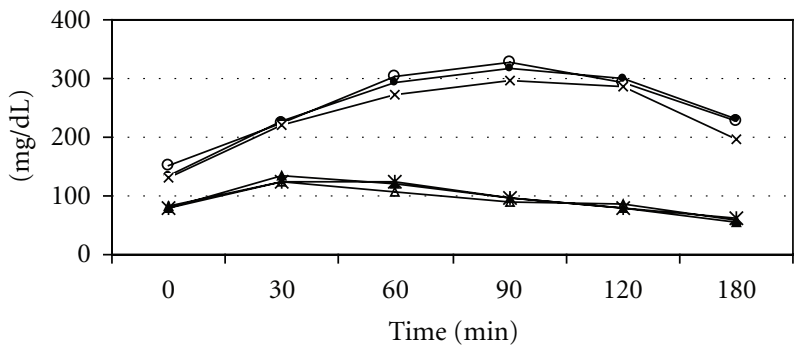

Figure 1: Mean serum glucose level at timed intervals during glucose tolerance test for 10 diabetic and 10 healthy participants. Mean serum glucose levels in $\mathrm{mg} / \mathrm{dL}$ without (o) and with $125(\bullet)$ and $250 \mathrm{mg}(\times)$ ingestion of Tinospora crispa diabetic participants, and without $(\triangle)$ and with $125(\Delta)$ and $250 \mathrm{mg}(*)$ ingestion of Tinospora crispa in healthy participants.

by trapezoidal rule, and means were tested for significance by paired $t$-test. Mean glucose and insulin blood levels of all subjects were calculated for each time point. $P<0.05$ was considered statistically significant.

\section{Results}

All of the 20 participants who had enrolled completed the study. At the dosage used there were no adverse effects reported by our subjects. During the treatment period no elevations in serum transaminase were detected. The baseline characteristics of the participants are shown in Table 1.

3.1. Glucose Levels with and without Ingestion of Tinospora crispa. Table 2 shows incremental serum glucose AUC (time 0 to $180 \mathrm{~min}$ ) over the baseline in $\mathrm{mg} \mathrm{min} / \mathrm{mL}$ for $75 \mathrm{~g}$ glucose ingestion with and without 125 or $250 \mathrm{mg}$ of $T$. crispa for each participant. The mean serum glucose AUC in both diabetic and healthy participants was not significantly different between with and without $T$. crispa. In diabetic participants the mean serum glucose AUC were slightly lesser when $250 \mathrm{mg}$ of $T$. crispa was ingested, but not reaching statistical significance (478 and $444 \mathrm{mg} \mathrm{min} / \mathrm{mL}$, resp., $P=$ 0.57). The mean glucose levels at each time interval showed small differences with T. crispa ingestion (Figure 1). 
TABLE 2: Mean of $3 \mathrm{~h}$ total area under the curve (AUC) glucose and 3-h total AUC insulin for $75 \mathrm{~g}$ oral glucose tolerance test performed with and without 125 or $250 \mathrm{mg}$ of Tinospora crispa.

\begin{tabular}{|c|c|c|c|c|c|c|}
\hline & \multicolumn{3}{|c|}{$3 \mathrm{~h}$ total AUC for glucose ( $\mathrm{mg} \mathrm{min} / \mathrm{mL})$} & \multicolumn{3}{|c|}{$3 \mathrm{~h}$ total AUC insulin $(\mathrm{mIU} \mathrm{min} / \mathrm{mL})$} \\
\hline & $\begin{array}{c}\text { Without } T \text {. } \\
\text { crispa }\end{array}$ & $\begin{array}{c}125 \mathrm{mg} T . \\
\text { crispa }\end{array}$ & $250 \mathrm{mg}$ T. crispa & $\begin{array}{c}\text { Without } T . \\
\text { crispa }\end{array}$ & $\begin{array}{c}125 \mathrm{mg} T . \\
\text { crispa }\end{array}$ & $\begin{array}{c}250 \mathrm{mg} T \\
\text { crispa }\end{array}$ \\
\hline DM & $478 \pm 135$ & $475 \pm 102$ & $444 \pm 117$ & $61 \pm 56$ & $50 \pm 37$ & $39 \pm 21$ \\
\hline Healthy & $165 \pm 25$ & $171 \pm 38$ & $171 \pm 30$ & $73 \pm 55$ & $85 \pm 34$ & $58 \pm 16$ \\
\hline
\end{tabular}

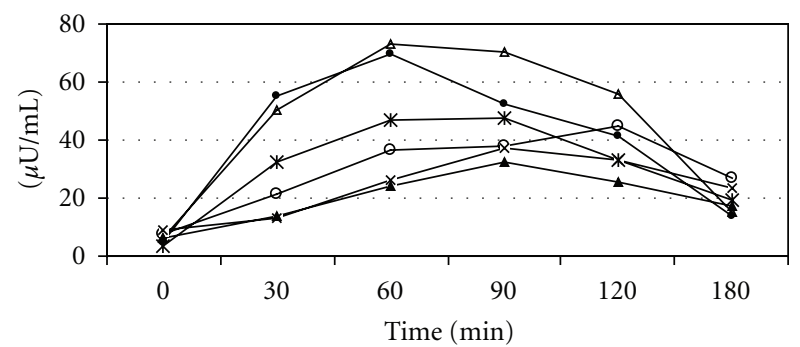

Figure 2: Mean serum insulin level at timed intervals during glucose tolerance test for 10 diabetic and 10 healthy participants. Mean serum insulin levels in $\mu \mathrm{U} / \mathrm{mL}$ without (o) and with 125 $(\bullet)$ and $250 \mathrm{mg}(\times)$ ingestion of Tinospora crispa in diabetic participants, and without $(\triangle)$ and with $125(\mathbf{\Delta})$ and $250 \mathrm{mg}\left({ }^{*}\right)$ ingestion of Tinospora crispa in healthy participants.

3.2. Insulin Levels with and without Ingestion of Tinospora crispa. Table 2 shows incremental insulin in $\mu \mathrm{Umin} / \mathrm{mL}$ AUC (time 0 to $180 \mathrm{~min}, 75 \mathrm{~g}$ glucose tolerance tests without and with 125 or $250 \mathrm{mg}$ of T. crispa) for each participant. Mean insulin AUC (Table 2) and mean levels at each time interval (Figure 2) in both diabetic and healthy participants varied, little with $T$. crispa ingestion.

\section{Discussion}

This study was unable to demonstrate the efficacy of T. crispa water extract to dry powder capsule for changes in areas under the serum glucose and insulin curves in healthy or diabetic subjects.

This result was inconsistent with other studies in animal model and metabolic syndrome subjects, Noor et al. [8] showed T. crispa aqueous extract to the drinking water for one week. Fasting blood glucose levels were significantly lower and serum insulin levels were significantly higher in treated diabetic rats $(10.4 \pm 1.0 \mathrm{mmol} / \mathrm{l}$ and $12.8 \pm$ $1.1 \mu \mathrm{U} / \mathrm{mL}$, resp.) compared to untreated diabetic controls $(17.4 \pm 1.7 \mathrm{mmol} / \mathrm{l}$ and $8.0 \pm 0.7 \mu \mathrm{U} / \mathrm{mL}$, resp.). Kongkathip et al. [9] found that the water extract of T. crispa caused a $13.9-15.6 \%$ reduction of serum glucose levels in normal rats after 120-minute oral feeding while $70 \%$ ethanol extract decreased serum glucose levels by $8.9-13.0 \%$ after 120 minute. Acute toxicity testing showed that LD50 values of water extracts are about $20-24 \mathrm{~g} / \mathrm{kg}$. It was suggested that the water extract of T. crispa is highly safe. Sriyapai et al. [7] presented metabolic syndrome patients who received $250 \mathrm{mg}$ twice a day T. crispa dry powder capsule for 2 months can reduce fasting blood glucose significantly from baseline $(6.29 \pm 10.47 \mathrm{mg} / \mathrm{dL}, P<0.01)$.

on the other hand, Sangsuwan et al. [5] showed that T. crispa had no efficacy for therapy in patients with type 2 DM who did not respond to oral hypoglycemic drugs since there were no significant changes in fasting serum glucose between those collected at baseline and during the study period in either group ( 250 and $245 \mathrm{mg} / \mathrm{dL}$, resp.) or glycosylated hemoglobin (10.3 and $11.2 \%$, resp.). Our study demonstrated that $T$. crispa can not significantly reduce mean serum glucose AUC in diabetic patient but can show a trend to reduce mean glucose AUC 478 to $444 \mathrm{mg} \mathrm{mL} / \mathrm{min} .250 \mathrm{mg}$ of T. crispa may not be adequate dosage to reduce serum glucose and stimulate insulin and another reason is that it may not last long enough to show the effect of treatment. Therefore, we need further investigation about adequate dose of T. crispa to reduce serum glucose and stimulate insulin secretion in type 2 diabetic patients.

\section{Conclusion}

The results suggest that Tinospora crispa ingestion cannot affect serum glucose and insulin levels in healthy subjects or patients with type 2 diabetes mellitus.

\section{Acknowledgments}

This work was supported by National Innovation Agency of Thailand. Special thanks are expressed to Mrs. Ngampong Kongkathip for her help in the study.

\section{References}

[1] W. Aekplakorn, R. P. Stolk, B. Neal et al., "The prevalence and management of diabetes in Thai adults: the International Collaborative Study of Cardiovascular Disease in Asia," Diabetes Care, vol. 26, no. 10, pp. 2758-2763, 2003.

[2] S. S. Ajgaonkar, "Herbal drugs in the treatment of diabetes mellitus," International Diabetes Federation Bulletin, vol. 24, pp. 10-19, 1979.

[3] H. Noor and S. J. H. Ashcroft, "Antidiabetic effects of Tinospora crispa in rats," Journal of Ethnopharmacology, vol. 27, no. 1-2, pp. 149-161, 1989.

[4] H. Noor and S. J. H. Ashcroft, "Pharmacological characterisation of the antihyperglycaemic properties of Tinospora crispa extract," Journal of Ethnopharmacology, vol. 62, no. 1, pp. 7-13, 1998.

[5] C. Sangsuwan, S. Udompanthurak, S. Vannasaeng, and V. Thamlikitkul, "Randomized controlled trial of Tinospora crispa for additional therapy in patients with type 2 diabetes mellitus," 
Journal of the Medical Association of Thailand, vol. 87, no. 5, pp. 543-546, 2004.

[6] N. Kongkathip, P. Dhumma-upakorn, B. Kongkathip, K. Chawananoraset, P. Sangchomkaeo, and S. Hatthakitpanichakul, "Study on cardiac contractility of cycloeucalenol and cycloeucalenone isolated from Tinospora crispa," Journal of Ethnopharmacology, vol. 83, no. 1-2, pp. 95-99, 2002.

[7] C. Sriyapai, R. Dhumma-upakorn, S. Sangwatanaroj, N. Kongkathip, and S. Krittiyanunt, "Hypoglycemic effect of tinospora crispa dry powder in outpatients with metabolic syndrome at king chulalongkorn memorial hospital," Journal of Health Research, vol. 23, no. 3, pp. 125-133, 2009.

[8] H. Noor, P. Hammonds, R. Sutton, and S. J. H. Ashcroft, "The hypoglycaemic and insulinotropic activity of Tinospora crispa: studies with human and rat islets and HIT-T15 B cells," Diabetologia, vol. 32, no. 6, pp. 354-359, 1989.

[9] N. Kongkathip, S. Jnakana, B. Kongkathip et al., "Extraction and purification of hypoglycemic agent from Tinospora Crispa," Final report, Bangkok: Department of Chemistry, Faculty of Science, Kasetsart University, 2006. 

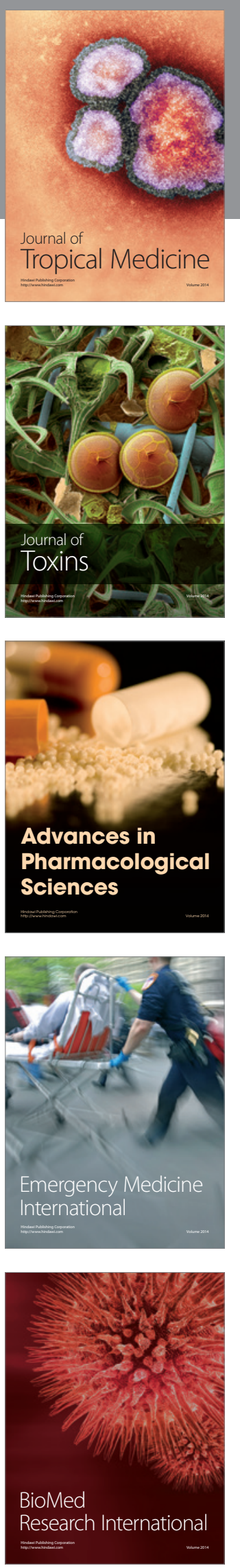
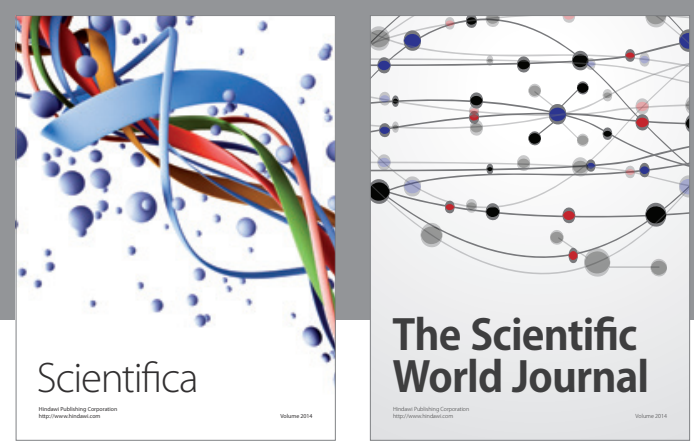

The Scientific World Journal
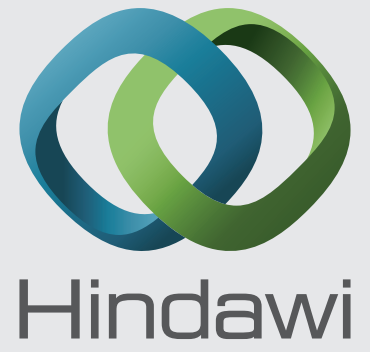

Submit your manuscripts at

http://www.hindawi.com
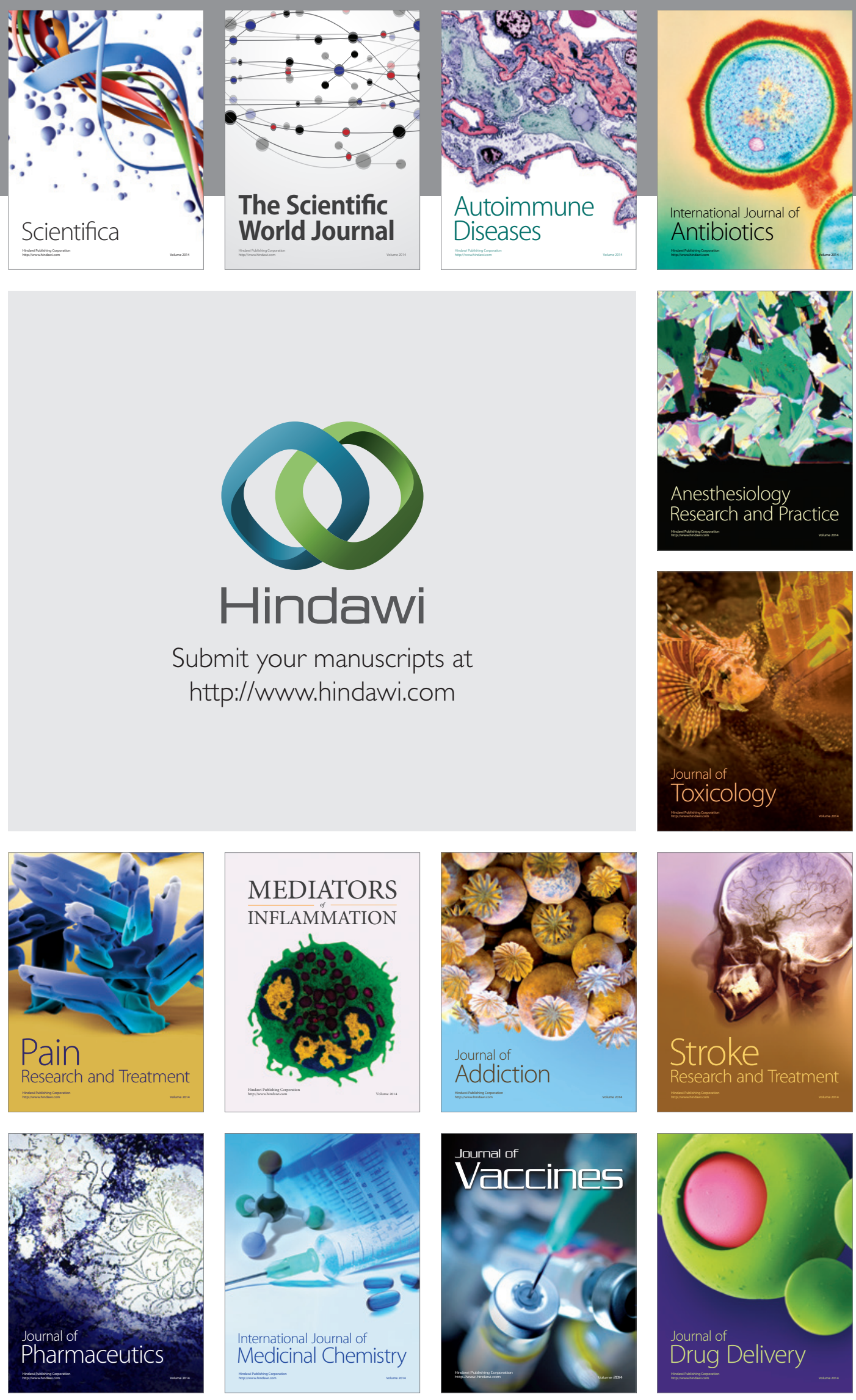